\title{
A PRÁTICA DO AUXILIAR DE ENFEMAGEM DO PROGRAMA SAÚDE DA FAMÍLIA
}

\author{
Helena Eri Shimizu' \\ Jane Lynn G. Dytz ${ }^{1}$ \\ Maria da Glória Lima² \\ Ana Socorro de Moura ${ }^{3}$
}

Shimizu HE, Dytz JLG, Lima MG, Moura AS. A prática do auxiliar de enfermagem do programa saúde da família. Rev Latino-am Enfermagem 2004 setembro-outubro; 12(5):713-20.

Este trabalho tem como objetivo conhecer a prática do auxiliar de enfermagem que atua no Programa Saúde da Família, identificando suas atividades cotidianas, bem como facilidades e dificuldades encontradas no seu trabalho. Optou-se pela abordagem qualitativa, utilizando-se a técnica de grupo focal, com participação de 34 auxiliares de enfermagem do Distrito Federal. Constatou-se que os auxiliares desenvolvem uma série de atividades, tanto de caráter individual como coletivo, com forte influência do modelo clínico de atenção e diferentes graus de complexidade, tais como: cadastramento das famílias, avaliação clínica sumária, atividades de grupo, procedimentos técnicos, visitas domiciliares, vigilância sanitária e epidemiológica. Os profissionais relatam que encontram facilidade na formação de vínculo com a clientela, porém se queixam da escassez de cursos de educação continuada, indefinição quanto as suas reais atribuições e falta de coordenação local. Conclui-se que o programa precisa redimensionar o papel desse profissional, resgatando sua função educativa junto à comunidade.

DESCRITORES: saúde da família; prestação de cuidados de saúde

This study aims to evaluate the practice of nursing auxiliaries in the Family Health Program, identifying their daily activities, as well as factors that facilitate or hinder their work. A qualitative approach was chosen, using the focal group technique, with the participation of 34 nursing auxiliaries from the Federal District, Brazil. It was found that the nursing auxiliaries carry out a variety of activities, both of individual and collective nature, heavily influenced by the clinical model and with different degrees of complexity, such as: family registration, brief clinical evaluation, group activities, technical procedures, home visits, sanitary and epidemiological vigilance in day care centers. The participants related that they found it easy to bond with the clientele, but complained of the shortage of continuing education courses and imprecision as to their true assignments and lack of local coordination. The authors conclude that the program must reassess the role of this professional, reemphasizing his educational function in the community.

DESCRIPTORS: family health; health care delivery

\section{LA PRÁCTICA DEL AUXILIAR DE ENFERMERÍA DEL PROGRAMA SALUD DE LA FAMILIA}

La finalidad de este trabajo es conocer la práctica del auxiliar de enfermería que actúa en el Programa Salud de la Familia, identificando sus actividades cotidianas, así como facilidades y dificultades encontradas en su trabajo. Fue adoptada una aproximación cualitativa, utilizándose la técnica de grupo focal, con participación de 34 auxiliares de enfermería del Districto Federal, Brasil. Se constata que los auxiliares desarrollan una serie de actividades, tanto en carácter personal como en colectivo, con fuerte influencia del modelo clínico de atención y diferentes grados de complejidad, tales como: catastro de las familias, evaluación clínica sumaria, actividades de grupo, procedimientos técnicos, visitas domiciliares, vigilancia sanitaria y epidemiológica. Los profesionales dicen que encuentran facilidad en la formación de vínculo con la clientela, pero se quejan de la falta de cursos de educación continuada, indefinición de sus reales atribuciones y falta de coordinación local. La conclusión es que el programa necesita redimensionar el papel de este profesional, rescatando su función educativa delante de la comunidad.

DESCRIPTORES: salud de la familia; prestación de atención en salud

\footnotetext{
${ }^{1}$ Professor Adjunto II, e-mail: shimizu@unb.br, e-mail: Jane@unb.br; ${ }^{2}$ Professor Adjunto I, e-mail: limamg@unb.br. Universidade de Brasília;

${ }^{3}$ Especialista em Psicodrama, Professor da Faculdade JK
} 
INTRODUÇÃO

A sociedade brasileira tem lutado para garantir o direito de assistência à saúde para todos. Dentre várias ações empregadas, merece destaque o Programa Saúde da Família (PSF), criado em 1994, pelo Ministério da Saúde (MS), com o propósito de ser uma estratégia para modificar o modelo assistencial vigente ${ }^{(1)}$, centrado na doença. O PSF valoriza os princípios da territorialidade, de vinculação com a população, de garantia de integralidade na atenção, de trabalho em equipe com enfoque multidisciplinar, de ênfase na promoção da saúde com fortalecimento das ações intersetoriais e de estímulo à participação da comunidade ${ }^{(2-3)}$.

Um novo modelo de saúde vem se delineando e tem, como foco principal, a atenção à família, considerando o meio ambiente, o estilo de vida e a promoção da saúde com os seus fundamentos básicos ${ }^{(3)}$.

No Distrito Federal (DF), uma primeira tentativa de reestruturação do sistema de saúde local ocorreu em 1996, na IV Conferência Distrital de Saúde, com a aprovação do Projeto REMA-SUS, que previa, dentre outros, um programa descentralizado, de abordagem comunitária, com atuação paralela à rede básica de saúde, denominado de Programa Saúde em Casa ${ }^{(4-5)}$. Esse programa teve início em 1997 e término no começo de 1999, quando ocorreu mudança do governo local. O governador eleito desmantelou esse programa, criando, em seguida, o PSF, que segue os moldes ditados pelo $M S^{(5-6)}$.

Em 2000, havia, aproximadamente, 134 equipes de Saúde da Família implantadas no DF ${ }^{(7)}$. Sabe-se que há várias dificuldades para a operacionalização desse programa no $\mathrm{DF}$, que vão desde o delineamento mais claro dos seus objetivos, até a falta de infra-estrutura física e de recursos humanos.

É importante destacar que seriam necessários estudos que analisassem a problemática do PSF. Contudo, constata-se que são escassos e, a grande maioria, relata a experiência de implantação do programa e/ou da necessidade de formação de recursos humanos voltada para essa área. Observa-se, também, carência de estudos que analisam o impacto do programa junto à população, fator de fundamental importância para avaliar se o programa está atingindo os objetivos propostos, bem como o desempenho dos profissionais que nele atuam.

Não há dúvidas sobre a necessidade de mudanças na capacitação e formação de recursos humanos para o alcance da cobertura assistencial de qualidade para os diversos segmentos coletivos ${ }^{(3)}$.

Os profissionais da área da saúde, principalmente das universidades públicas, têm participado da capacitação de recursos humanos para atuarem no PSF, em diversas regiões do país. Entretanto, reconhecem que não tem sido uma tarefa fácil devido a diversas dificuldades impostas por essa nova área de atuação.

Na nossa prática, como docentes do curso de Enfermagem, ao elaborarmos um curso para enfermeiros, voltado para a capacitação dos auxiliares de enfermagem (AE), deparamos com a dificuldade de especificar as ações desenvolvidas por esses profissionais, no cotidiano de trabalho no PSF, já que o próprio Ministério da Saúde define, de modo parcimonioso, as atribuições básicas ${ }^{(8) *}$ desse profissional, sem apontar desempenhos e/ou atividades específicas, conforme os diferentes graus de complexidade, inerentes a um trabalho com as famílias na comunidade.

Assim, a necessidade de investigar mais profundamente a prática do AE do PSF, essencial para elaboração de cursos de capacitação e atualização desses profissionais, motivou a realização deste estudo, que teve como objetivo conhecer as atividades desenvolvidas cotidianamente pelo auxiliar de enfermagem, dentro da equipe da Saúde da Família, identificando facilidades e dificuldades encontradas por esse profissional, para desenvolver o seu trabalho.

\section{TRAJETÓRIA METODOLÓGICA}

Trata-se de um estudo que utiliza a abordagem qualitativa, do tipo descritivo e exploratório. A pesquisa qualitativa permite a entrada para o mundo das representações sociais mais subjetivas, uma vez que

\footnotetext{
*As atribuições básicas do AE são: desenvolver, com os ACS, atividades de identificação das famílias de risco; contribuir, quando solicitado, com o trabalho dos ACS, no que se refere às visitas domiciliares; acompanhar as consultas de enfermagem dos indivíduos expostos às situações de risco, visando garantir uma melhor monitoria de suas condições de saúde; executar, segundo sua qualificação profissional, os procedimentos de vigilância sanitária e epidemiológica nas áreas de atenção à criança, à mulher, ao adolescente, ao trabalhador e ao idoso, bem como no controle da tuberculose, hanseníase, doenças crônico-degenerativas e infecto-contagiosas; participar da discussão e organização do processo de trabalho da unidade de saúde
} 
possibilita a fala espontânea, realista e natural, a não linearidade das respostas sobre realidades tipicamente não lineares ${ }^{(9)}$.

Para a coleta de dados, utilizou-se a técnica de grupos focais, sob coordenação das autoras. Realizaramse duas sessões de grupos focais, no mês de setembro de 2001, com duração de, aproximadamente, três horas e com a participação de $34 \mathrm{AE}$. Contamos com a participação de auxiliares de enfermagem que atuam nas regiões administrativas do DF: Brazlândia, Ceilândia, Gama, Guará, Núcleo Bandeirante, Paranoá, Recanto das Emas, Samambaia, Santa Maria, São Sebastião, Sobradinho, Taguatinga e Varjão, exceto Planaltina.

Inicialmente, os $A E$ foram informados sobre os objetivos do estudo e garantia do anonimato das informações. Todos os participantes assinaram o termo de consentimento livre e esclarecido. O Comitê de Ética da instituição autorizou a realização do estudo. Para facilitar o desenvolvimento das entrevistas grupais, utilizouse o seguinte roteiro: 1) Diga as principais atividades que você desenvolve no cotidiano de trabalho no PSF, tomando como base uma semana típica de trabalho; 2) Explique como você desenvolve essas atividades; 3) Quais as dificuldades/problemas que você encontra no cotidiano de trabalho? Posteriormente, as entrevistas oriundas das sessões de grupos focais foram transcritas na íntegra.

Para análise dos dados, optou-se pela análise de conteúdo, especificamente a análise temática ${ }^{(10)}$. Assim, a análise das entrevistas foi desenvolvida em três fases: a) pré-análise; b) exploração do material; c) tratamento e interpretação dos dados. No primeiro momento, realizaram-se diversas leituras flutuantes das entrevistas grupais. No segundo, a classificação dos conteúdos repetidos e/ou que destoavam nessas entrevistas e que deram origem a três temas, a saber: ações de caráter individual; ações de caráter coletivo e facilidades/ dificuldades enfrentadas pelos auxiliares. A seguir, será apresentada a análise dos temas apreendidos nos discursos.

\section{APRESENTAÇÃo E ANÁLISE DOS RESULTADOS}

Quanto à caracterização dos sujeitos participantes do estudo, 37,5\% tem idade entre $21-30$ anos, $50 \%$ entre 31-50 anos, e $12,5 \%$ acima de 50 anos; $70,8 \%$ deles residem na mesma comunidade em que trabalham. A maioria está no PSF desde sua implantação, todos concluíram o curso introdutório do PSF, e 58,3\% referem ter participado de outro curso de capacitação nos últimos três anos. Quanto à composição da equipe, um terço dos participantes relatou que sua equipe está completa, $42 \%$, que sua equipe está parcialmente completa (sem médico ou enfermeiro), e $25 \%$, incompleta (sem médico e enfermeiro).

Atividades de caráter individual desenvolvidas pelo auxiliar de enfermagem

Das atividades desenvolvidas pelos AE do PSF, de caráter individual, destacaram-se as de auxílio ao atendimento da demanda espontânea. É necessário salientar que diversas unidades do PSF têm implantado esse tipo de atendimento. Algumas unidades realizam atendimentos diários, e outras, em alguns dias reservados. Quando não há médico na equipe, os $\mathrm{AE}$ ficam com a responsabilidade de realizar a triagem e encaminhamento da população para outros serviços de saúde. Além da triagem de pacientes, que tem o propósito de controle e repressão da demanda, os $\mathrm{AE}$ realizam a pré-consulta da enfermeira ou do médico, como mostra a fala a seguir:

Crianças chegam, eu, como auxiliar, vou lá, vejo a temperatura, respiração, peso, né? Ouço o que a mãe está relatando, escrevo, passo pra enfermeira, a enfermeira dá outra avaliada, olha no ouvido, garganta. Se for o caso e ela mesma conseguir diagnosticar, ela vai passar alguma coisa, se não, a gente vai até o pediatra do posto, que nós não temos, e ele faz a avaliação da criança.

Outra atividade assumida pelos $\mathrm{AE}$, de caráter mais burocrático, é o auxílio ao médico no provimento de receitas para pacientes que fazem uso de medicações contínuas. Esses dados evidenciam que as atividades desenvolvidas pelos $A E$, relativas ao atendimento da demanda espontânea, têm a finalidade de reduzir a demanda, agilizar os atendimentos e auxiliar as ações médicas, especialmente a consulta médica do tipo pronto atendimento.

Esse tipo de atendimento caracteriza-se por atendimentos rápidos, pautados na queixa e conduta, sem nenhum tipo de vínculo dos usuários com os serviços de saúde. Alguns estudos mostram que esse modo de atendimento da população não pode ser considerado como uma forma específica de modelo assistencial, uma vez 
que responde, de forma passiva e simplificada, a uma demanda viciosamente estabelecida a partir de imagens socialmente construídas que concebem a saúde no seu pólo de negação, ou seja, a doença ${ }^{(11-12)}$. As atividades desenvolvidas pela equipe de enfermagem nesse tipo de atendimento caracterizam-se como atividades complementares às do médico ${ }^{(11)}$.

Os AE são também responsáveis pelos diversos procedimentos de enfermagem dos pacientes que procuram os serviços do PSF, como curativos, aplicação de injeção, verificação de pressão arterial, coleta de glicemia, etc. A maioria das unidades realiza, ainda, tratamentos e procedimentos no domicílio, principalmente em idosos ou clientes portadores de doenças crônicas. Numa freqüência menor, ocorre, também, o atendimento de emergência.

Foi possível verificar, por meio da identificação das atividades, de caráter individual, desenvolvidas pelos $\mathrm{AE}$, que as unidades do PSF têm empenhado esforços para realizar diversas atividades que têm como finalidade o atendimento da demanda espontânea, como a consulta médica e/ou de enfermagem, a depender do nível de complexidade e gravidade do quadro clínico do cliente, e ações que visam ao controle da doença, em detrimento das atividades de prevenção e promoção da saúde.

Enfim, esses dados demonstram que, embora a proposta do PSF represente uma mudança no modelo assistencial, em direção ao modelo epidemiológico, com assistência integral, continuidade e resolutividade, as equipes ainda seguem a lógica do modelo clínico de atenção à saúde, para o desenvolvimento das atividades.

Atividades de caráter coletivo desenvolvidas pelo auxiliar de enfermagem

Das atividades de caráter coletivo, os $A E$ destacaram a realização de cadastramento das famílias. Geralmente, esse procedimento, de responsabilidade do agente comunitário de saúde (ACS), é realizado quando as unidades do PSF são implantadas. Entretanto, no DF, as unidades do PSF precisam atualizar cadastramentos de famílias com muita freqüência, pois existem muitos migrantes chegando o tempo todo, possivelmente atraídos pela política de distribuição de lotes à população carente, praticada pelo governo do Distrito Federal.

Junto com o cadastramento das famílias, é realizado levantamento do perfil epidemiológico por meio do procedimento da morbidade referida. Esse procedimento, embora não seja tão preciso, sem dúvida alguma, representa um avanço no sentido de possibilitar o melhor conhecimento das necessidades da população e pode subsidiar a elaboração de planos de assistência à saúde coletiva, mais eficientes e eficazes.

Em regiões com alto índice de violência e criminalidade, os agentes de saúde têm auxiliado os demais elementos da equipe a se aproximarem das famílias, colocando-se, freqüentemente, em situação de risco, como mostra esta fala:

E sair sozinho não dá! A gente tem que sair com o agente porque ele conhece a área, ele mora lá. Então, ele sabe aonde tem boca de fumo, aonde que tem prostituição, aonde tem alcoólatras, assim não tem nem condições de você entrar!

Além dessas atividades, os auxiliares de enfermagem realizam visita domiciliar às famílias. Essa visita tem por finalidade: a identificação de problemas de saúde; o controle e/ou tratamento de doenças ou grupos de risco (crianças com vacinas atrasadas); a investigação de casos suspeitos e a busca ativa de doenças de notificação compulsória, como mostra a fala a seguir:

Se for numa casa, vamos dizer assim que o cachorro morreu, aí a gente vai ter que ir lá, como é a busca ativa, aí, a gente vai com a enfermeira. Ela monta todo um relatório e manda pra identificação, tá!

Os AE participam das atividades desenvolvidas junto aos grupos, inclusive de algumas atividades alternativas, como: automassagem e caminhadas. Esses grupos são organizados segundo as faixas etárias ou portadores das mesmas doenças crônico-degenerativas, a saber:

Nós montamos um grupo de adolescentes; nós estamos com quarenta e oito adolescentes. Inicialmente, nós falamos pra eles o seguinte: 'Nós vamos montar um grupo de dança, certo?' Nós arrumamos um professor, um professor da área mesmo. Ele se predispôs a fazer isso, isso desde outubro do ano passado (...) trabalhamos com eles: planejamento familiar, sexualidade e união da família, laços paternais e amigos, tudo isso! A gente faz palestras com eles.

Com relação às atividades desenvolvidas para esses grupos, evidencia-se que os profissionais da equipe do PSF utilizam métodos pedagógicos tradicionais e não se sentem preparados para desenvolver técnicas mais participativas, porque a maioria dos auxiliares sente que não recebeu instrumentalização necessária durante a sua formação e ao ingressar no programa. Nesse sentido, é 
importante destacar que o $\mathrm{AE}$ procura desenvolver o que acha que seria melhor para a sua comunidade, baseandose, principalmente, em orientações contidas nos manuais dos diversos programas desenvolvidos pelo Ministério da Saúde. Porém, falta o envolvimento dos outros membros da equipe nessas atividades ou mesmo um acompanhamento mais de perto do próprio enfermeiro da equipe.

No meu curso de enfermagem, eu tive a parte de saúde pública, quer dizer, eu tenho muito material em casa, revistas minhas, todas as minhas caixas, tudo está recortado para ver alimentação de hipertenso, diabético, a prevenção do câncer de mama, o câncer de colo uterino. Você não consegue material! Aonde meu Deus, aonde eu vou arrumar uma mão pra me ensinar como é que mexe!

Os $A E$ evidenciam, também, que atuam em escolas e creches. Nessas instituições, realizam tratamentos simples e algumas atividades de prevenção de doenças:

Então, a gente trabalha muitos problemas de intervenção do problema de pediculoses, né? É piolho, sarna, tem aqueles mais importante (...) cortes com vidros, perfurações de pregos, esses negócios, assim

Verificou-se que as equipes do PSF têm se empenhado para desenvolver algumas atividades de caráter coletivo. Nesse sentido, nota-se que o cadastramento das famílias e, posteriormente, as buscas ativas em domicílio têm possibilitado o conhecimento do perfil epidemiológico da população. Entretanto, percebe-se que esses dados deveriam ser mais usados e explorados pelas equipes, para a realização de planejamento das ações de saúde de caráter individual e coletivo.

No que se refere às ações voltadas para os diferentes grupos, percebe-se que as equipes esforçamse para desenvolvê-las, porém sentem que não estão devidamente preparados, ou seja, sentem que os conhecimentos e as habilidades ainda são precários para o desempenho dessas atividades. Como resultado, rezalizam ações semelhantes aos desenvolvidos pela rede básica de saúde.

Em suma, verifica-se que as atividades de caráter coletivo ainda são bastante incipientes, portanto exigem avaliações mais aprofundadas que permitam mensurar as respostas para as necessidades da população e, conseqüentemente, o alcance da saúde coletiva. Verificouse que o AE executa poucas ações de orientação sanitária, seja no âmbito individual ou coletivo, o que deveria ser, de acordo com as diretrizes do programa, uma de suas principais funções.
Facilidades e dificuldades encontradas pelo auxiliar de enfermagem no seu dia-a-dia

De modo geral, os participantes relataram que são bem recebidos pela população e possuem facilidade de se entrosar com ela, pois já estão no PSF há mais de 2 anos e conhecem bem as necessidades e os problemas da comunidade, como fica evidente na seguinte fala:

A comunidade já conhece a gente, a gente já conhece bem a comunidade!

Essa receptividade por parte da comunidade faz com que os $\mathrm{AE}$ se sintam úteis e orgulhosos do seu desempenho. Outro fator que os motiva é a retroalimentação que recebem constantemente das famílias atendidas, sobretudo as expressões de agradecimento. Mas esse reconhecimento social do trabalho realizado pelas equipes do PSF é considerado uma conquista relativamente recente já que, no início, o programa enfrentou muita resistência e incredulidade por parte da população.

Hoje, a gente, eu acho, que a gente conquistou o nosso espaço! Mas, no início, a gente não estava com muito crédito!

Mesmo assim, os AE consideram que a população ainda desconhece a principal função do programa - a prevenção de doença e a promoção da saúde possivelmente por falta de maior divulgação e esclarecimento acerca da proposta do PSF.

Está sendo pouco divulgado o saúde da família. (...) Eu não vejo na televisão dizer que é promoção de saúde, é prevenção. A comunidade tem que ver isso porque só a gente falando não vai adiantar!

Verifica-se que a integração entre os centros de saúde e PSF é um desafio a ser enfrentado por ambos, como ilustra a fala que se segue:

Eu acho que um dos maiores desafios deste programa (...) é o engajamento com os postos de saúde, essa união, essa parceria e esse alojamento conjunto, quer dizer, isto é a gente se agrega lá e a gente tem que se dar bem e dividir tudo.

O depoimento acima mostra, também, que algumas equipes do PSF, por não terem sede própria, estão instaladas no centro de saúde. Como conseqüência, precisam dividir o mesmo espaço físico e os recursos materiais. Isso, por um lado, tem forçado uma maior interação entre alguns serviços, por outro, demonstra a precariedade de condições de infra-estrutura física para as equipes, como ilustram estes depoimentos:

A gente está lá, já que é dentro mesmo do posto, o salão 
deles, eles deram metade do salão pra gente, e, o salão a gente dividiu em três salinhas, fez o consultório, sala de curativos. Então a gente trabalha em uma parceria muito boa com o posto, então assim, a modo de sempre que a gente precisar do posto deles, sempre que eles precisarem da gente a gente está ali também. A gente não tem problema nenhum não, até mesmo de material, às vezes falta um pacote de material pra fazer um curativo, eu vou lá no posto e peço: 'Gente, vocês têm aí?'.

Percebe-se, entretanto, que a relação entre esses dois serviços ainda é bastante frágil, pois tem se estabelecido apenas em cima da relação de ajuda entre essas unidades para atender a grande demanda de pacientes.

A minha equipe tem mil setecentas e sessenta famílias, então, com certeza antes do PSF entrar, isso tudo era do posto. $A$ demanda era muito grande! Então, quê que nós fizemos? Como nós somos três equipes, dividiu toda a população pra cada equipe junto com o centro de saúde que não tem equipe ainda, entendeu? Então eles querendo ou não, a gente está ajudando, porque ficou dividido, você entendeu?

Apenas algumas unidades, por ocuparem o mesmo espaço físico, tentam desenvolver, conjuntamente, algumas atividades que visam otimizar $\mathrm{o}$ atendimento da população, como mostra esta fala:

Aí, a gente entrou em um consenso com o posto de saúde. O quê que a gente faz agora - todas as reuniões, hipertenso, diabéticos, $C D$ e gestante - a gente da equipe está lá, um auxiliar está sempre lá nessas reuniões que nessas reuniões a gente pega os nomes das gestantes e das crianças pra depois visitar.

Nota-se, porém, que o sistema de referência e contra referência entre centros e postos de saúde e o PSF é ineficiente. Observa-se grande dificuldade e falta de agilidade no encaminhamento de pacientes para realizar atendimento com especialista, sendo que o sucesso e a agilidade dos encaminhamentos, na maioria das vezes, dependem, em grande parte, dos relacionamentos interpessoais e informalidade. Essa situação assemelhase às enfrentadas por outros tipos de unidades em diversas regiões do país, o que tem dificultado o alcance dos princípios do Sistema Único de Saúde $\mathrm{e}^{(13-14)}$.

Muito difícil! Pra se marcar uma consulta de ginecologia no Posto do Núcleo Bandeirante, nós não conseguimos, nem a enfermeira, é muito difícil! A pessoa tem que ir 5 horas da manhã para a fila e não adianta ir com o cartão e explicar a situação porque não marca. Muito difícil! Mesma coisa o acompanhamento, cardiologia!

Outra dificuldade enfrentada pelo PSF, destacada pelos auxiliares de enfermagem, é a falta de recursos humanos, ou seja, muitas equipes estão incompletas. No DF, isso ocorre em decorrência de uma política do governo local de implantação rápida do programa. Assim, as equipes convivem, principalmente, com falta de médicos, como mostra a fala abaixo:

Realmente, uma das maiores dificuldades do programa é essa: de não ter médico. Porque os pacientes, às vezes, precisam da medicação e você não pode prescrever a medicação e a gente fica sem saber o que fazer.

Essa situação cria uma série de dificuldades para as equipes, pois a população faz muita pressão sobre os demais profissionais. Deve-se salientar que, em decorrência da predominância do modelo biomédico de assistência, durante muitos anos, a população acredita que apenas o médico pode resolver os seus problemas de saúde.

A figura do médico é que é muito importante, porque tem tanta coisa que você pode dizer para um paciente, mas que o médico também diz. Talvez hoje ele acredite mais no médico do que em você. Mas a partir de amanhã e com o passar do tempo, ele passa a ver que você é um profissional de saúde e o que você fala é baseado também em livros, em fatos e em conhecimentos. Porque é isso que nós estamos fazendo aqui, trocando experiências, isso enriquece cada um!

Não há dúvidas sobre a importância do médico nas equipes do PSF. Contudo, fica evidente que o PSF precisa realizar um enorme trabalho junto à população, para que aprendam a valorizar os outros campos de conhecimento, inclusive o popular. Nessa perspectiva, a aproximação do senso comum, do diálogo, facilitará o ato de conquistar o conhecimento, para que juntos, os técnicos da saúde e comunidade possam analisar mais criticamente a realidade cotidiana ${ }^{(15)}$.

Os AE salientaram que, além do médico, faltam também outros profissionais em diversas equipes do PSF, como, por exemplo, enfermeiros ou odontólogos. Destacase também que, em algumas regiões, devido ao grande número de problemas sociais existentes, seria imprescindível a presença permanente de uma assistente social na equipe do PSF. Esses dados revelam que não há dúvidas de que, para desenvolver ações de grande complexidade e diversidade, como as requeridas pelo PSF, exige-se uma atuação interdisciplinar e multidisciplinar. Assim, seria necessário incorporar outros profissionais para ampliar o atendimento das necessidades da população. 
Outro problema levantado pelos auxiliares de enfermagem refere-se à falta de adicional de insalubridade, devido aos riscos a que estão expostos ao trabalharem na comunidade com animais domésticos, usuários soro positivos, além de exposição a situações violentas:

O risco que a gente corre de não estar dentro do posto é, primeiro, a boca de fumo. A gente entra dentro da boca de fumo e a gente se depara com situações igual ontem - que eu estava fazendo um curativo numa paciente e o filho dela começou com briga com outro maconheiro e o outro puxou a faca e eu lá, fazendo curativo!

Os auxiliares demonstraram, também, que as equipes de regiões rurais e/ou de grande abrangência convivem com o problema de transporte para o desenvolvimento das atividades. Por fim, os AE afirmam ter dificuldades de relacionamento com os coordenadores do PSF, pois alguns são bastante autoritários, como ilustram os depoimentos abaixo:

Ela é muito autoritária e essa é uma reclamação que a gente não tem o que fazer! Vocês deveriam ouvir as pessoas lá! Eu também acho que ela coloca o dedo na cara da gente, assim (...). É tipo, assim, um sargentão e nós sofremos lá! (...) Como é que uma equipe vai pra frente se a coordenadora é desse jeito? Porque uma equipe é uma equipe!

Além disso, percebem que alguns enfermeiros não têm preparo adequado para coordenar o trabalho em equipe. $O$ trabalho em equipe constitui-se uma ferramenta fundamental para o desenvolvimento do trabalho junto às famílias. Contudo, sabe-se que esse é um desafio a ser enfrentado pelo programa. São dimensões importantes do trabalho em equipe: a articulação das ações e a interação dos profissionais ${ }^{(16)}$. Estas possibilitam a prática do trabalho, em equipe, onde a comunicação entre os profissionais faz parte do dia a dia de trabalho e os agentes operam a articulação das intervenções técnicas por meio das mediações simbólicas da linguagem.

Verifica-se que as equipes do PSF convivem com dificuldade de integração com os centros e postos de saúde, pois a relação entre esses serviços baseia-se apenas na divisão de recursos físicos, materiais e de demanda de clientela. Esses dados revelam a necessidade de articulação entre essas unidades, para o desenvolvimento de um planejamento estratégico em conjunto, a fim de atender às demandas da população.

Os dados demonstram que a insuficiência de recursos humanos tem causado problemas para as equipes e para a população. Além disso, por dificultar a elaboração de planos de ação em equipe para a comunidade, coloca em risco a credibilidade do programa.
Por fim, verificou-se a necessidade de melhorar as condições de trabalho, a infra-estrutura física, recursos materiais e humanos. Destaca-se, ainda, a necessidade de fortalecer o trabalho em equipe, criando oportunidade para os profissionais socializarem, com o restante dos membros da equipe, as situações vivenciadas junto à comunidade.

\section{CONSIDERAÇÕES FINAIS}

Inicialmente, é necessário destacar que este estudo evidencia apenas um recorte da problemática vivenciada pelo PSF do DF, uma vez que foi realizada, apenas, a análise das atividades desenvolvidas pelo PSF, pela ótica de um grupo de auxiliares de enfermagem.

Verificou-se, por meio da identificação das atividades realizadas pelos auxiliares de enfermagem, que as atividades de caráter individual, desenvolvidas pelas equipes do PSF do DF, ainda se pautam no modelo clínico de atenção à saúde. Nesse sentido, os dados mostram, também, que as equipes gastam grande parte do tempo realizando atendimento individual da demanda espontânea. Certamente, contribuem para a manutenção desse modelo de atendimento pelas equipes do PSF do DF: a pressão feita pela população doente, devido às condições degradantes de vida; o perfil atual dos profissionais, cuja maioria tem uma formação centrada no modelo clínico, e ainda a insuficiência de estudos e reflexões que analisem as dificuldades enfrentadas pelo programa.

As equipes do DF têm realizado esforços para conhecer o perfil epidemiológico da população atendida, utilizando o procedimento da morbidade referida, embora não façam uso de procedimentos mais rigorosos da epidemiologia clássica. Isso já representa um grande avanço, principalmente porque podem auxiliar na elaboração de planos de assistência à saúde coletiva, realmente voltada para as necessidades da população.

Os dados mostram que as equipes do PSF têm se empenhado em realizar atividades de caráter coletivo. Entretanto, ao se analisarem essas atividades, especialmente as atividades desenvolvidas com grupos de adolescente, idosos e hipertensos, fica evidente que precisam ser reavaliados, no sentido de verificar se realmente têm causado impacto na saúde e na qualidade de vida da população. O profissional de nível médio conhece bem a realidade das famílias brasileiras de baixa 
renda, mas tem pouco preparo formal para lidar com questões socioculturais, ou mesmo estratégias próprias do trabalho comunitário.

Identificou-se, também, que as condições de trabalho das equipes são bastante precárias, pois faltam recursos humanos, materiais e físicos. Muitos profissionais enfrentam inúmeros riscos, inclusive de vida, para desempenhar suas atividades diárias. Além disso, trabalham, freqüentemente, sem coordenação direta (o que Ihes confere um certo grau de autonomia), porém acabam assumindo responsabilidades além dos limites de suas atribuições profissionais.

\section{REFERÊNCIAS BIBLIOGRÁFICAS}

1. Ministério da Saúde (BR). Saúde dentro de casa: programa de saúde da família. Brasília(DF): Ministério da Saúde; 1994. 2. Souza HM. Entrevista com a diretora do departamento de atenção básica - SPS/MS - Saúde da Família. Rev Bras Enfermagem 2000 dezembro; 53(n. especial):7-16.

3. Rocha SMM, Almeida MCP. O processo de trabalho da enfermagem em saúde coletiva e a interdisciplinariedade. Rev Latino-am Enfermagem 2000 dezembro; 8(6):96-101. 4. Governo Distrito Federal (DF). Plano de Saúde do Distrito Federal de 1998. Brasília (DF): Secretaria da Saúde; 1998. 5. Santos ER, Shimizu HE. Breve histórico da assistência à saúde no Distrito Federal: caracterização de cenário na perspectiva da Saúde Coletiva - CIPESC. In: Chianca T, Antunes MJM, organizadoras. A classificação internacional das práticas de enfermagem em saúde coletiva -CIPESC. Brasília (DF): Associação Brasileira de Enfermagem;1999. p.66-79.

6. Hildebrand EM, Flores O, Costa MM Neto. Formação Acadêmica em saúde familiar: relato de uma experiência multiprofissional. Rev Bras Enfermagem 2000 dezembro; 53(n. especial):95-102.

7. Governo do Distrito Federal (BR). Programa Saúde da Família. Brasília (DF): Secretaria de Saúde; 2000.

8. Ministério da Saúde (BR). Saúde da Família: uma estratégia para a orientação do modelo assistencial. Brasília (DF): Ministério da Saúde; 1997.

9. Demo P. Pesquisa qualitativa. Busca de equilíbrio entre forma e conteúdo. Rev Latino-am Enfermagem 1998 abril; 6(2):89-104.

10. Minayo MCS. Desafio do conhecimento. $4^{\underline{a}}$ ed. São Paulo (SP): Hucitec;1997.

11. Almeida MCP. O trabalho de enfermagem e sua articulação com o processo de trabalho em saúde coletiva - rede básica de saúde em Ribeirão Preto. [tese]. Ribeirão Preto (SP): Escola de Enfermagem/USP; 1991.

12. Oliveira DC, Siqueira AAF, Alvarenga AT. Práticas sociais em saúde: uma releitura à luz da teoria das representações sociais. In: Oliveira DC, Moreira AASP, organizadoras. Estudos interdisciplinares de representação social. Goiânia (GO): Cultura e Qualidade; 1998. p 163-90.
Em suma, foi possível verificar, por meio da identificação e análise das atividades desenvolvidas pelos auxiliares de enfermagem, que grande parte do trabalho diário do PSF depende do trabalho desenvolvido pelo auxiliar de enfermagem. É preciso redimensionar o papel desse profissional dentro da equipe de Saúde da Família, reconhecendo e aceitando a sua contribuição para o alcance das metas do programa, e investir na capacitação de um profissional cada vez mais capaz de assistir aos problemas de saúde mais comuns e de manejar novos saberes que, por meio de processos educativos, promovam a saúde e previnam doenças em geral.

13. Chiesa AM. Assistência à saúde das mulheres no município de Taboão da Serra com diagnóstico de displasia ou carcinoma cérvico-uterino: problematização do sistema de referência e contra-referência. Rev Bras Enfermagem 1992;45:28-35.

14. Juliani MCM; Ciampone MHT. Organização do Sistema de referência e contra referência no contexto do sistema único de saúde: a percepção de enfermeiros. Rev Esc Enfermagem USP 1999; 33(4):323-33.

15. Palha PF, Lima GM, Mendes IJM. Programa de integração comunitária: em busca de novas estratégias e novos sentidos à vida. Rev Latino-am Enfermagem 2000 abril; 8(2):5-10.

16. Ciampone MHT, Peduzzi M. Trabalho em equipe e trabalho em grupo no programa saúde da família. Rev Bras Enfermagem 2000 dezembro; 53(n. especial):143-7. 